\title{
EFFECT OF PHYSICAL THERAPY ON IMPAIRMENTS IN COVID-19 PATIENTS FROM INTENSIVE CARE TO HOME REHABILITATION: A RAPID REVIEW
}

Ruben DEBEUF, MSc ${ }^{1,2,3}$, Eva SWINNEN, PhD ${ }^{1,2,3}$, Tine PLATTIAU, BSc ${ }^{1}$, Ann DE SMEDT, MD, PhD $2,4,5$, Elisabeth DE WAELE, MD, PhD ${ }^{6}$, Stijn ROGGEMAN, MD, PhD ${ }^{4}$, Marc SCHILTZ, MD, PhD ${ }^{4}$, David BECKWÉE, PhD ${ }^{1,3,7}$ and Emma DE KEERSMAECKER, MSc ${ }^{1,2,3}$

From the ${ }^{1}$ Rehabilitation Research, Department of Physiotherapy, Human Physiology and Anatomy, Faculty of Physical Education and Physiotherapy, Vrije Universiteit Brussel, Brussels, Belgium, ${ }^{2}$ Center for Neurosciences (C4N), Vrije Universiteit Brussel, Brussels, Belgium, ${ }^{3}$ Brussels Human Robotic Research Center (BruBotics), Vrije Universiteit Brussel, Brussels, Belgium, ${ }^{4}$ Department of Physical Medicine and Rehabilitation, Universitair Ziekenhuis Brussel, Brussels, Belgium ${ }^{5}$ STIMULUS Consortium (reSearch and TeachIng neuroModULation Uz bruSsel), Universitair Ziekenhuis Brussel, Brussels, Belgium, ${ }^{6}$ Intensive Care Unit, Universitair Ziekenhuis Brussel, Brussels, Belgium and ${ }^{7}$ Research Group MOVANT, Department of Rehabilitation Sciences and Physiotherapy (REVAKI), University of Antwerp, Wilrijk, Belgium

Objective: Guidelines regarding physical therapy for COVID-19 patients are often based on expert opinion. Recent clinical trials have reported effects on several rehabilitation outcomes in COVID-19 patients. This review summarizes the effects of physical therapy in COVID-19 patients.

Data sources: PubMed, Web of Science and Scopus databases were systematically searched for studies investigating the effect of any physical therapy modality on impairments in adult COVID-19 patients. Included studies were (non)-randomized controlled trials, pre-experimental studies, and cohort studies in which a pre-post analysis was performed.

Data extraction: After the screening process, data of interest were extracted from eligible studies and their risk of bias was assessed. Included outcome measures were divided into 3 groups: pulmonary function, physical function, and psychosocial function.

Data synthesis: A total of 15 studies were included in this review. Physical therapy seems to have positive effects on pulmonary function, physical function, and psychosocial function. However, these effects differ between clinical settings (e.g. home care, intensive care unit, inpatient units). Due to the low-tomoderate quality of the included studies, no robust conclusions can be drawn.

Conclusion: Further high-quality research is required, taking into account the different clinical settings, in order to draw conclusions about the effectiveness of physical therapy on impairments in COVID-19 patients.

Key words: COVID-19; physical therapy; rehabilitation.

Accepted Sep 21, 2021; Epub ahead of print Oct 11, 2021

J Rehabil Med 2021; 53: jrm00237

Correspondence address: Emma De Keersmaecker, Rehabilitation Research, Department of Physiotherapy, Human Physiology and Anatomy, Vrije Universiteit Brussel, Brussels, Belgium. E-mail: emma. de.keersmaecker@vub.be

$\mathrm{T}$ he coronavirus disease 2019 (COVID-19) pandemic, caused by severe acute respiratory syndrome coronavirus 2 (SARS-CoV-2), has been endangering global health since early 2020. Worldwide, over 237 million cases of COVID-19 have been registered, of

\section{LAY ABSTRACT}

Guidelines regarding physical therapy for COVID-19 patients are often based on expert opinion or on evidence from studies of physical therapy in patients with other diseases. More and more clinical studies are investigating the effect of physical therapy on the recovery of COVID-19 patients. Prior to this review, the importance of physical therapy for COVID-19 patients was not clear. This review summarizes the effects of physical therapy in COVID-19 patients. We reviewed and assessed the quality of the existing literature on this topic. Fifteen studies with a total of 1,341 COVID-19 patients were included in this review. Physical therapy appears to improve lung function, physical function, and psychosocial function in COVID-19 patients. However, the effect can differ between clinical settings; for example, home care, intensive care unit, or other inpatient units. Due to the lowto-moderate quality of the included studies, no robust conclusion can be drawn. Further high-quality research is needed, taking into account the different clinical settings.

whom over 4.8 million have died (1). However, this is probably an underestimation, as COVID-19 patients can be asymptomatic and thus remain unnoticed (1).

COVID-19 impacts, among other things, both the physical and mental well-being of patients. Approximately $14 \%$ of COVID-19 patients will require hospitalization, and extremely severe cases will need intensive care. Such patients can develop a range of dysfunctions, such as lung function impairments, neurological impairments, reduced physical capacity, muscle weakness, and psychological and cognitive impairments (2). Clinical practice guidelines state that these complications can be countered with appropriate physical therapy management as part of a multidisciplinary approach $(3,4)$. Research prior to the COVID-19 pandemic has shown that patients with acute lung injury may still have significant physical impairments, such as balance problems and muscle weakness, even years after discharge, which, in turn, can increase the risk of falls (5). Baricich et al.'s cross-sectional study (6) found that, 3-6 months after discharge, 32\% of COVID-19 patients still had impaired physical performance. These findings emphasize the importance of rehabilitation, even after patients are discharged from hospital. 
Several reviews and guidelines have summarized the role of physical therapy in rehabilitation of COVID-19 patients (7-9); however, due to the urgent need for guidelines on how to treat these patients, these are mostly based on expert opinion or on evidence from patients with other lung diseases, and not on evidence from recent literature concerning COVID-19. Meanwhile, many clinical trials about the rehabilitation of COVID-19 patients have already been conducted and published, highlighting the need for an update of the current guidelines. To the best of our knowledge, no systematic review has described the role of physical therapy in the rehabilitation of COVID-19 patients in both the acute and subacute phases of the disease. Therefore, the aim of this systematic review is to describe the role of physical therapy in the rehabilitation of COVID-19 patients in all phases of recovery.

\section{METHODS}

Study design

This rapid review was conducted according to the Preferred Reporting Items for Systematic Reviews and Meta-Analysis (PRISMA) statement for reporting systematic reviews.

\section{Eligibility criteria}

Studies were included in this review if they met following inclusion criteria:

- Type of participants: studies that included adult COVID-19 patients ( $>18$ years old).

- Type of intervention: studies that investigated the effect of any physical therapy modality (e.g. breathing exercises, aerobic training, muscle strengthening, relaxation) on COVID-19 impairments.

- Type of outcome: studies that assessed the pre-post and/ or post-follow up effect of physical therapy on COVID-19 impairments. Outcomes were divided into 3 categories: pulmonary function (e.g. oxygen supplementation, oxygen saturation, forced vital capacity), physical function (e.g. 6-min walk test (6MWT), Barthel Index (BI), muscle strength), and psychosocial function (e.g. anxiety, depression, quality of life (QoL)).

- Type of study design: non-, quasi- or randomized controlled trials (RCTs), pre-experimental studies, or cohort studies were included. Non-clinical trials (e.g. guidelines, (systematic) reviews), case reports/case series, methodological papers and congress participations were excluded. Studies had to be published in English, Dutch or French.

\section{Information sources and search strategy}

Electronic searches were conducted using following 3 databases: PubMed, Web of Science and Scopus, with a final search date of 4 May 2021. The search strategy was developed by combining search terms related to the population (COVID-19-related keywords) and the intervention (keywords related to physical therapy interventions). To limit the number of studies to screen, some filters were used in all databases. In PubMed, the clinical trial filter was used. Reviews were already excluded in Web of Science and only experimental studies were included. In the
Scopus database, a filter was used to exclude reviews and to include only articles published in English, Dutch and French. The full electronic search is shown in Appendix S1.

\section{Study selection}

Identification and selection of eligible studies was performed with the use of the web-based application Rayyan (11). After excluding duplicates, titles and abstracts were screened to identify relevant studies. If studies were considered relevant or, in case of doubt, full paper copies were retrieved and their eligibility checked. If the full text was not available, the corresponding author was contacted to obtain a copy. If a copy could not be obtained, the study was excluded.

\section{Data collection process and data items}

The data items of interest were extracted by one reviewer (TP) using the Cochrane data extraction form template for RCTs and non-RCTs. This form was double-checked and completed by 2 other authors (RD and EDK). From each individual study, the following information was extracted: $(i)$ patient characteristics (population, number, sex, age), (ii) therapy of the intervention group and, if applicable, the control group, (iii) outcome measures, and (iv) the setting (inpatient intensive care unit (ICU), inpatient no ICU, outpatient (home care)). Only outcomes for which the significance of the difference between the pre- and post-treatment values had been calculated, were included in the data extraction form. Other outcome measures were disregarded, since they do not reflect the effect of physical therapy. If important data were missing in a study, no assumptions were made, and no conclusions were drawn based on these data.

\section{Risk of bias assessment}

To assess the risk of bias, different tools were used, depending on the study design of the included article. To assess the risk of bias of a RCT, the second version of the Cochrane risk-of-bias tool for randomized trials (ROB II) was used (12). If the study was identified as either a non-RCT or a pre-experimental study, the Cochrane Risk Of Bias In Non-Randomized Studies tool (ROBINS-I) was used (13). Lastly, to assess the risk of bias in cohort studies, the Quality in Prognostic Studies (QUIPS) tool was utilized (14). Since the cohort studies included in this review could not be identified as prognostic studies, the domain "prognostic factor measurement" was not applicable and thus not included in the risk of bias assessment. No other adaptations were made to the tools used in this review.

\section{RESULTS}

\section{Study selection}

The total search yielded 2,863 relevant articles in PubMed, Web of Science and Scopus. Fig. 1 shows the flow diagram of the entire study selection process. In total, 15 studies were included, of which 2 were RCTs, 1 was a non-RCT, 6 were preexperimental studies, and 6 were cohort studies.

\section{Study characteristics}

Table I and Table II list more detailed information about the study characteristics of the (non-) RCTs (Table I) and the pre-experimental and cohort studies (Table II). 


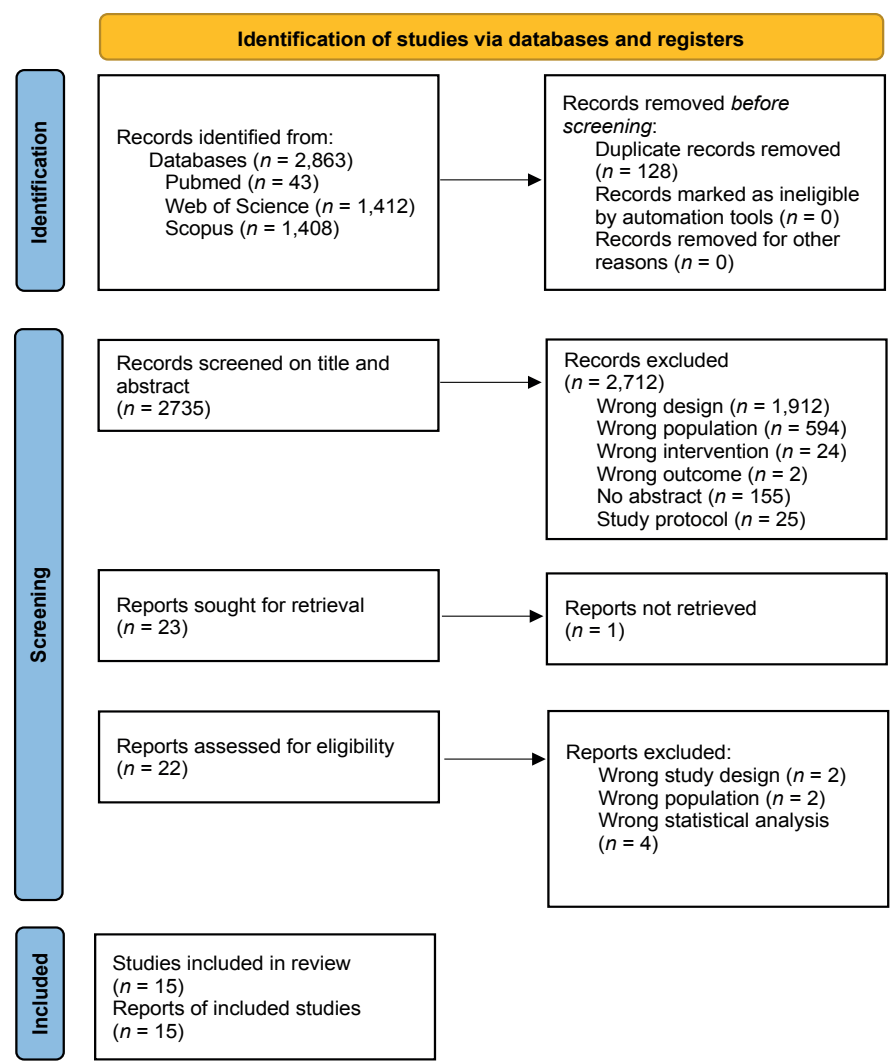

Table I. Characteristics of included (non-)randomized clinical trials assessing the effect of physical therapy on impairments in COVID-19 patients

\begin{tabular}{|c|c|c|c|c|c|c|c|c|c|c|c|c|c|}
\hline \multirow[b]{2}{*}{ Study } & \multicolumn{5}{|c|}{ Intervention group } & \multicolumn{5}{|l|}{ Control group } & \multirow[b]{2}{*}{ Outcomes } & \multicolumn{2}{|c|}{ Setting } \\
\hline & Population & $\mathrm{N}$ & $\% \mathrm{~F}$ & $\begin{array}{l}\text { Age, } \\
\text { years }\end{array}$ & Therapy & Population & $\mathrm{N}$ & $\% \mathrm{~F}$ & $\begin{array}{l}\text { Age, } \\
\text { years }\end{array}$ & Therapy & & ICU & $\mathrm{nICU} \mathrm{HC}$ \\
\hline \multicolumn{14}{|l|}{$\mathrm{RCT}$} \\
\hline \multirow{10}{*}{$\begin{array}{l}\text { Liu et } \\
\text { al. } 2020 \\
(15)\end{array}$} & \multirow{10}{*}{$\begin{array}{l}\text { Elderly } \\
\text { COVID-19 } \\
\text { patients }\end{array}$} & \multirow[t]{10}{*}{36} & \multirow[t]{10}{*}{33.3} & \multirow{10}{*}{$\begin{array}{l}69.4 \\
(8.0)\end{array}$} & \multirow{5}{*}{$\begin{array}{l}\text { (1) respiratory muscle } \\
\text { training with threshold PEP } \\
3 \times 10 \text { breaths, } 60 \% \text { MEP, } 1 \\
\text { min rest } \\
\text { ( } 2 \text { ) cough exercises } 3 \times 10 \\
\text { active coughs }\end{array}$} & Elderly & \multirow{10}{*}{36} & 30.6 & \multirow{10}{*}{$\begin{array}{r}68.9 \\
(7.6)\end{array}$} & \multirow[t]{10}{*}{ NI } & \multirow{5}{*}{$\begin{array}{l}\text { FEV1 } \\
\text { FVC } \\
\text { DLCO } \\
6 M W T \\
\text { FIM }\end{array}$} & & \multirow[t]{10}{*}{$x$} \\
\hline & & & & & & \multirow[t]{9}{*}{ COVID-19 patients } & & & & & & & \\
\hline & & & & & & & & & & & & & \\
\hline & & & & & & & & & & & & & \\
\hline & & & & & & & & & & & & & \\
\hline & & & & & \multirow{4}{*}{$\begin{array}{l}\text { (3) diaphragmatic training } \\
30 \text { max. voluntary } \\
\text { contractions with weight } \\
(1-3 \mathrm{~kg}) \\
\text { (4) stretching exercises } \\
\text { respiratory muscles }\end{array}$} & & & & & & \multirow{5}{*}{$\begin{array}{l}\text { SF-36 } \\
\text { SAS } \\
\text { SDS } \\
\text { t0: baseline } \\
\text { t1: } 6 \text { weeks }\end{array}$} & & \\
\hline & & & & & & & & & & & & & \\
\hline & & & & & & & & & & & & & \\
\hline & & & & & & & & & & & & & \\
\hline & & & & & $\begin{array}{l}\text { (5) home exercise: pursed } \\
\text { lip breathing and cough } \\
\text { training }\end{array}$ & & & & & & & & \\
\hline \multirow{3}{*}{$\begin{array}{l}\text { Özlü } \\
2021 \text { et } \\
\text { al(16) }\end{array}$} & \multirow{3}{*}{$\begin{array}{l}\text { COVID-19 } \\
\text { patients }\end{array}$} & \multirow{3}{*}{33} & \multirow{3}{*}{36} & \multirow{3}{*}{$\begin{array}{l}36.48 \\
(11.63)\end{array}$} & \multirow{3}{*}{$\begin{array}{l}2 \text { sessions/day for } 20-30 \\
\text { min progressive muscle } \\
\text { relaxation exercises, taught } \\
\text { via } C D\end{array}$} & \multirow{3}{*}{ COVID-19 patients } & \multirow{3}{*}{34} & & (11.90) & & RCSQ & & \\
\hline & & & & & & & & & & & t0: baseline & & \\
\hline & & & & & & & & & & & t1: 5 days & & \\
\hline Non-RCT & & & & & & & & & & & & & \\
\hline Abodonya & Recovered & 21 & 19.1 & 48.3 & Incentive breathing & Recovered & 21 & 23.8 & 47.8 & Incentive & FVC & & $x$ \\
\hline $\begin{array}{l}\text { et al. } \\
2021\end{array}$ & $\begin{array}{l}\text { COVID-19 } \\
\text { patients weaned }\end{array}$ & & & $(8.5)$ & $\begin{array}{l}\text { exercises } 2 \text { sessions/day for } \\
2 \text { weeks }\end{array}$ & $\begin{array}{l}\text { COVID-19 patients } \\
\text { weaned from }\end{array}$ & & & $(9.2)$ & $\begin{array}{l}\text { breathing } \\
\text { exercise } 2 \times /\end{array}$ & FEV1 & & \\
\hline (17) & from ventilation & & & & + inspiratory muscle & ventilation & & & & day for 2 weeks & DSI & & \\
\hline & & & & & training: daily 2 sessions of & & & & & & EQ-5D-3L & & \\
\hline & & & & & 6 inspiratory cycles with 60 & & & & & & 6MWT & & \\
\hline & & & & & s rest afterwards, threshold & & & & & & t0: baseline & & \\
\hline & & & & & set at $50 \%$ MIP & & & & & & t1: 2 weeks & & \\
\hline
\end{tabular}

Continuous values are reported as mean (SD). CD: compact disk; DLCO: diffusing capacity for carbon monoxide; DSI: dyspnoea severity scale; EQ-5D-3L: EuroQuality-5Demensions-3Levels: \%F: percentage female; FEV1: forced expiratory volume in $1 \mathrm{~s}$; FIM: Functional Independence Measure; FVC: forced vital capacity; HC: home care; ICU: patients who stayed at the intensive care unit; max.: maximum; MEP: maximum expiratory pressure; MIP: maximum inspiratory pressure; N: number; NI: no information; nICU: patients who did not stay at the intensive care unit; PEP: positive expiratory pressure; RCSQ: Richards-Campbel Sleep Questionnaire; RCT: randomized controlled trial; SAS: self-rating anxiety scale; SDS: self-rating depression scale; SF-36: 36-Item Short Form Health Survey; 6MWT: 6-min walk test; STAI: State-Trait Anxiety Inventory. 
p. 4 of 16 R. Debeuf et al.

Table II. Characteristics of included pre-experimental and cohort studies of the effect of physical therapy on impairments in COVID-19 patients

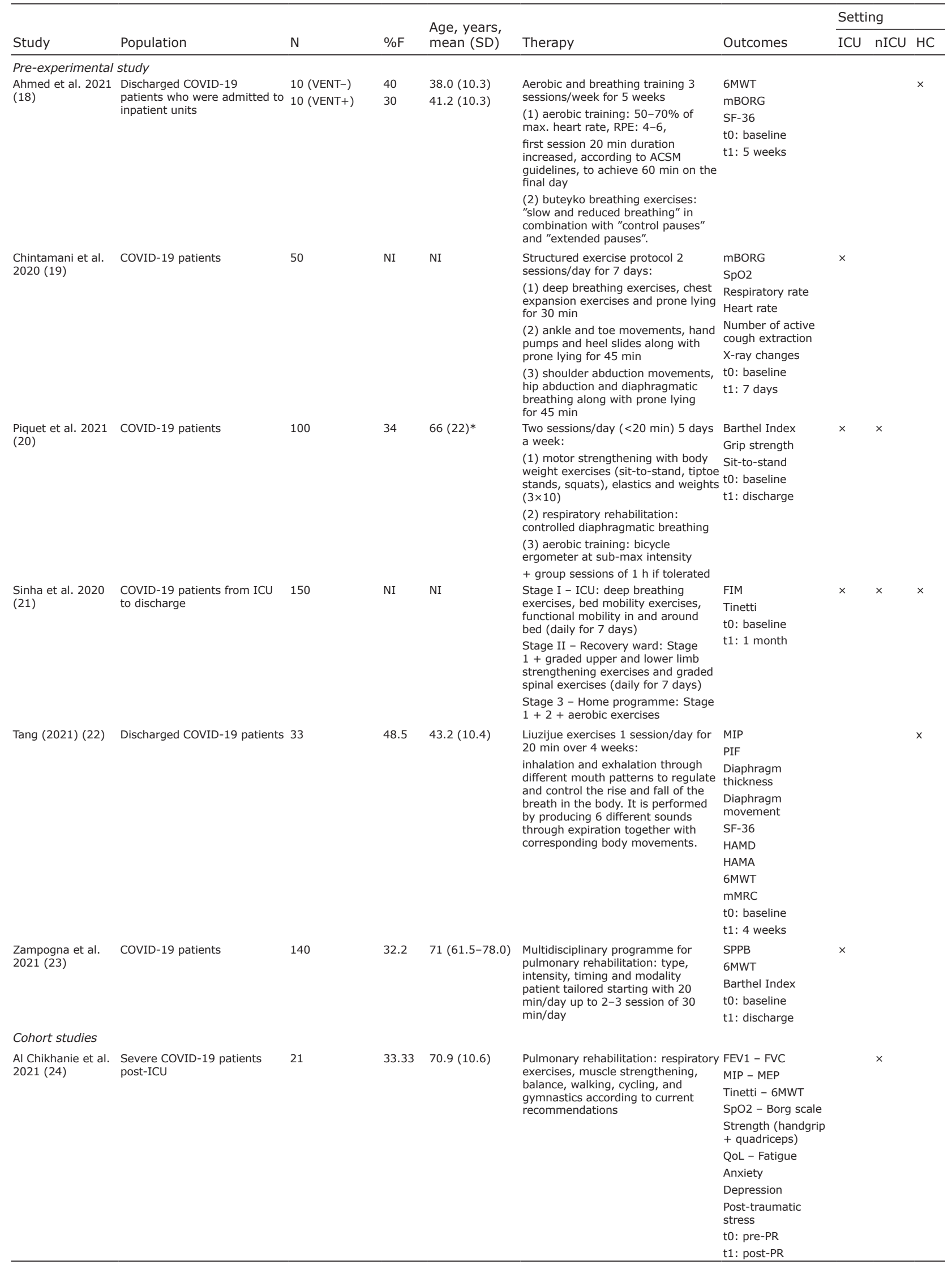


Table II. Conts.

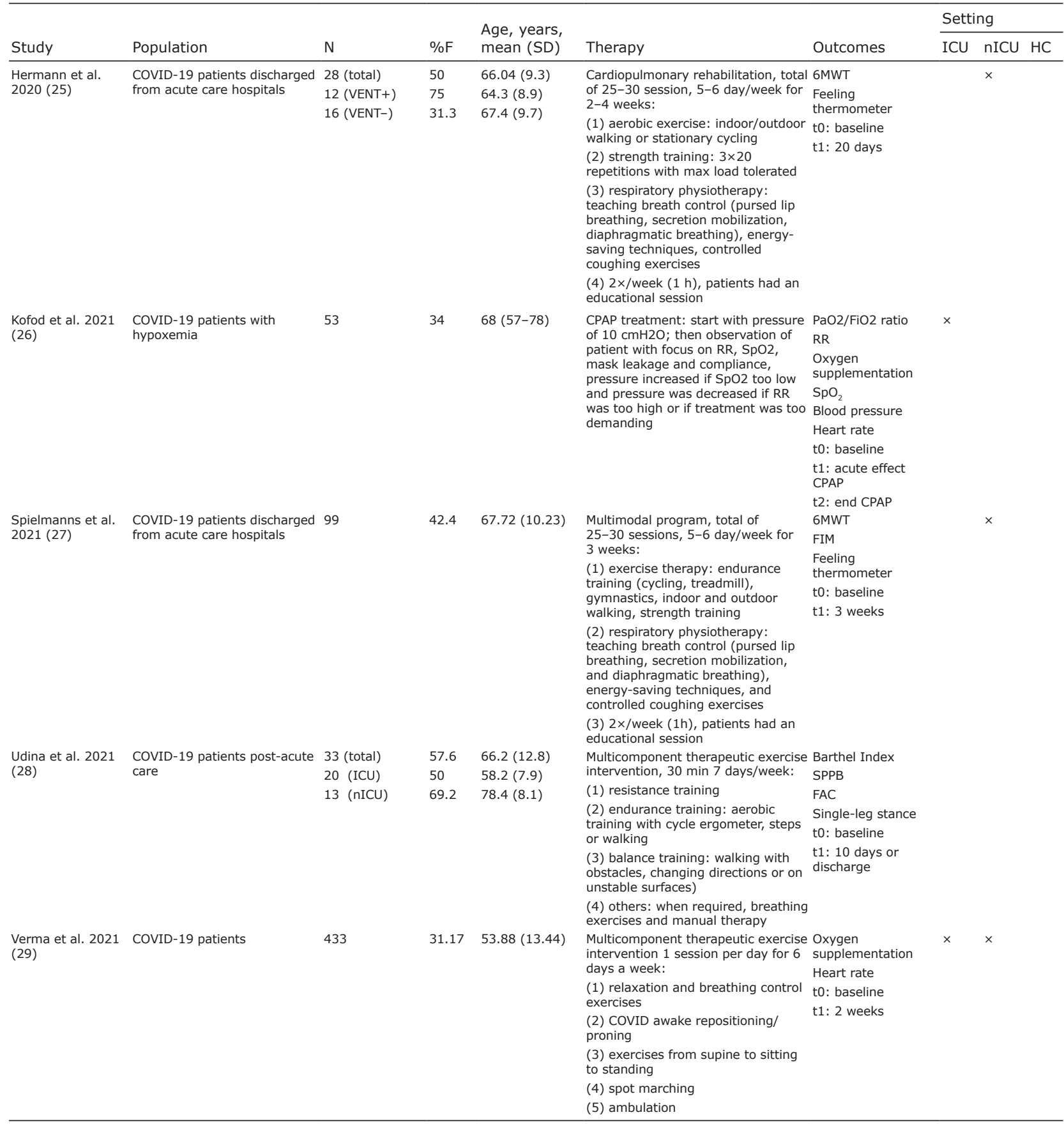

Continuous values are reported as mean (SD) or median (IQR)*.

$\%$ F: percentage female; FAC: Functional Ambulation Category; FIM: Functional Independence Measure; HC: home care; ICU: patients who stayed at the intensive care unit; mBORG: modified BORG scale; mMRC: modified Medical Research Council; N: number; NI: no information; nICU: patients who did not stay at the intensive care unit; POMA: Performance Oriented Mobility Assessment; SF-36: 36-Item Short Form Health Survey; 6MWT: 6-min walk test; SpO ${ }_{2}$ : oxygen saturation; RPE: rating of perceived exertion; SPPB: Short Physical Performance Battery; VENT+: patients who received mechanical ventilation; VENT-: patients who did not receive mechanical ventilation.

Patient characteristics. In total, 1,341 COVID-19 patients were included (sample size: $10-433$, a mean of $37 \%$ women, mean age range 33.1-78.4 years). One study focused specifically on elderly COVID-19 patients $(\geq 65$ years of age) (15). Six studies included active COVID-19 patients, of which 2 studies were on patients admitted to the ICU $(19,26), 2$ studies were on patients admitted to other inpatient care units $(16,24)$, and 2 studies included both $(20,29)$. Five studies included recovered COVID-19 patients who were still receiving inpatient rehabilitation 
p. 6 of 16 R. Debeuf et al.

Table III. Risk of bias assessment of the randomized controlled trials

\begin{tabular}{|c|c|c|c|c|c|c|}
\hline Study & $\begin{array}{l}\text { Risk of bias arising from } \\
\text { randomization process }\end{array}$ & $\begin{array}{l}\text { Risk of bias due to } \\
\text { deviations from intended } \\
\text { interventions }\end{array}$ & $\begin{array}{l}\text { Risk of bias due to } \\
\text { missing outcome data }\end{array}$ & $\begin{array}{l}\text { Risk of bias in } \\
\text { measurement of outcome }\end{array}$ & $\begin{array}{l}\text { Risk of bias in } \\
\text { selection of the } \\
\text { reported studies }\end{array}$ & $\begin{array}{l}\text { Overall risk of } \\
\text { bias }\end{array}$ \\
\hline $\begin{array}{l}\text { Lui et al. } 2020 \\
\text { (15) }\end{array}$ & + & - & $?$ & + & + & - \\
\hline $\begin{array}{l}\text { Özlü Lui et al. } \\
2021(16)\end{array}$ & + & $?$ & - & $?$ & + & - \\
\hline
\end{tabular}

Table IV. Risk of bias assessment of the non-randomized controlled trials and pre-experimental studies

\begin{tabular}{|c|c|c|c|c|c|c|c|c|}
\hline Study & $\begin{array}{l}\text { Bias due to } \\
\text { confounding }\end{array}$ & $\begin{array}{l}\text { Bias in selection } \\
\text { of the participants } \\
\text { into the study }\end{array}$ & $\begin{array}{l}\text { Bias in } \\
\text { classification of } \\
\text { interventions }\end{array}$ & $\begin{array}{l}\text { Bias due to deviations } \\
\text { from intended } \\
\text { interventions }\end{array}$ & $\begin{array}{l}\text { Bias due to } \\
\text { missing data }\end{array}$ & $\begin{array}{l}\text { Bias in } \\
\text { measurement } \\
\text { of outcomes }\end{array}$ & $\begin{array}{l}\text { Bias in } \\
\text { selection of the } \\
\text { reported result }\end{array}$ & Overall \\
\hline $\begin{array}{l}\text { Abodonya et al. } \\
2021 \text { (17) }\end{array}$ & $?$ & + & + & + & + & + & + & $?$ \\
\hline $\begin{array}{l}\text { Ahmed et al. } 2021 \\
\text { (18) }\end{array}$ & $?$ & + & + & + & + & + & + & $?$ \\
\hline $\begin{array}{l}\text { Chintamani et al. } \\
2020 \text { (19) }\end{array}$ & $?$ & + & + & + & $?$ & + & + & - \\
\hline $\begin{array}{l}\text { Piquet et al. } 2021 \\
\text { (20) }\end{array}$ & $?$ & - & + & + & $?$ & + & + & - \\
\hline $\begin{array}{l}\text { Sinha et al. } 2020 \\
(21)\end{array}$ & $?$ & + & + & + & $?$ & - & + & - \\
\hline $\begin{array}{l}\text { Tang et al. } 2021 \\
\text { (22) }\end{array}$ & $?$ & + & + & + & + & + & + & $?$ \\
\hline $\begin{array}{l}\text { Zampogna et al. } \\
2021 \text { (23) }\end{array}$ & $?$ & - & + & + & - & + & + & - \\
\hline
\end{tabular}

+: low risk of bias; -: high risk of bias; ?: some concerns.

Table V. Risk of bias assessment of the cohort studies

\begin{tabular}{|c|c|c|c|c|c|}
\hline Study & Study participation & Study attrition & Outcome measurement & Study confounding & Statistical analysis and reporting \\
\hline $\begin{array}{l}\text { Al Chikhanie et al. } 2021 \\
\text { (24) }\end{array}$ & - & + & $?$ & ? & + \\
\hline Hermann et al. 2020 (25) & - & $?$ & + & $?$ & - \\
\hline Kofod et al. 2021 (26) & - & + & $?$ & $?$ & + \\
\hline $\begin{array}{l}\text { Spielmanns et al. } 2021 \\
\text { (27) }\end{array}$ & + & $?$ & + & ? & ? \\
\hline Udina et al. 2021 (28) & $?$ & $?$ & $?$ & $?$ & $?$ \\
\hline
\end{tabular}

+: low risk of bias; -: high risk of bias; ?: some concerns.

$(17,18,22,25,27)$, while 2 studies included discharged COVID-19 patients who received home care $(18,22)$. The remaining study investigated the effect of physical therapy on COVID-19 impairments in patients from ICU to home care (21).

Interventions. A variety of physical therapy interventions were included in the studies. Several subgroups could be distinguished: respiratory muscle training (strengthening and stretching) (15), breathing and cough exercises $(15,17)$, prone lying $(19,29)$, continuous positive airway pressure (CPAP) (26), aerobic training $(18,20,21,23,25,27,28)$, physical exercises (muscle strengthening, mobilizations, bed mobility) (19-21, 23-25, 27-29), progressive muscle relaxation and educational sessions $(25,27)$.

Outcome measures. COVID-19 impairments were divided in 3 subgroups: pulmonary function, physical function, and psychosocial function. Several pulmonary outcome measures (e.g. forced expiratory volume, dyspnoea, breathlessness, oxygen saturation, heart rate) were assessed in 8 studies $(15,17,18,19,22,24,26$, 29). Eleven studies assessed 1 or more physical outcome measures, such as the 6MWT, Functional Independence Measure, and grip strength $(15,17,18,20-25,27,28)$. Psychological outcomes were investigated in 8 studies and included questionnaires regarding QoL, anxiety and depression, sleep, fatigue, post-traumatic stress, and well-being (15-18, 22, 24, 25, 27).

Risk of bias assessment. The risk of bias of the RCTs, non-RCTs, pre-experimental studies and cohort studies are shown in Table III, Table IV and Table V.

One of the main limitations of most of the included studies was that no confounding variables were defined and accounted for $(17-19,24)$. Another prevalent badly scored item was the risk of bias due to missing outcomes. In some studies, this item scored poorly because more than $5 \%$ of the participants' data was missing and no appropriate analysis was conducted or it was not described how missing data were handled $(15,16,27$, 29). In other studies, no information was given about 
Table VI. Results per outcome: pulmonary function

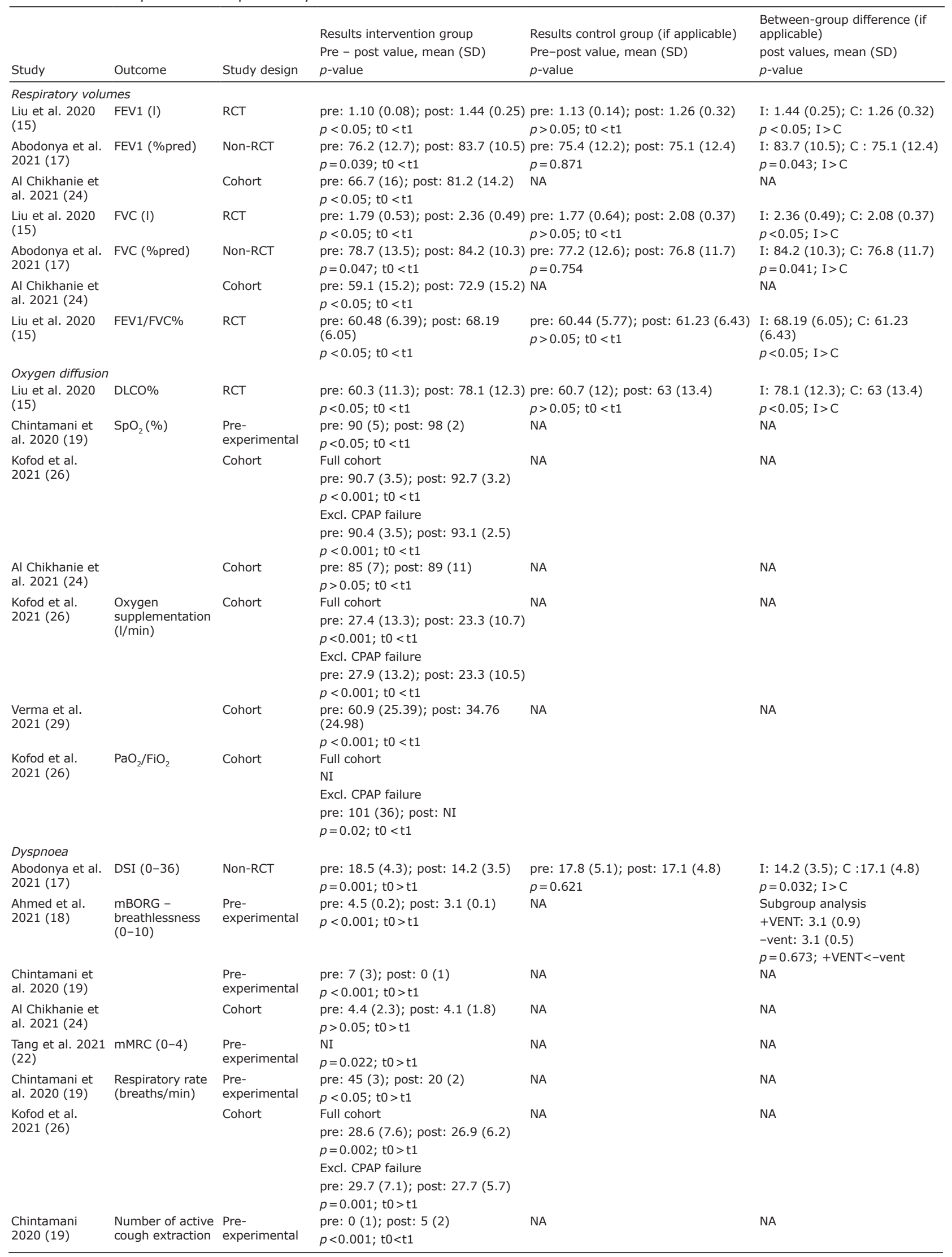


Table VI. Cont.

\begin{tabular}{|c|c|c|c|c|c|}
\hline Study & Outcome & Study design & $\begin{array}{l}\text { Results intervention group } \\
\text { Pre - post value, mean (SD) } \\
p \text {-value }\end{array}$ & $\begin{array}{l}\text { Results control group (if applicable) } \\
\text { Pre-post value, mean (SD) } \\
p \text {-value }\end{array}$ & $\begin{array}{l}\text { Between-group difference (if } \\
\text { applicable) } \\
\text { post values, mean (SD) } \\
p \text {-value }\end{array}$ \\
\hline $\begin{array}{l}\text { Chintamani et } \\
\text { al. } 2020(19)\end{array}$ & X-ray changes & $\begin{array}{l}\text { Pre- } \\
\text { experimental }\end{array}$ & $\begin{array}{l}\mathrm{NI} \\
p<0.05 ; \mathrm{NI}\end{array}$ & NA & NA \\
\hline $\begin{array}{l}\text { Tang et al. } 2021 \\
(22)\end{array}$ & $\operatorname{MIP}\left(\mathrm{cmH}_{2} \mathrm{O}\right)$ & $\begin{array}{l}\text { Pre- } \\
\text { experimental }\end{array}$ & $\begin{array}{l}\text { MD: } 13.46(20.06) \\
p<0.001 ; \text { t } 0>t 1\end{array}$ & NA & NA \\
\hline \multicolumn{6}{|c|}{ Respiratory muscle function } \\
\hline $\begin{array}{l}\text { Al Chikhanie et } \\
\text { al. } 2021(24)\end{array}$ & & Cohort & $\begin{array}{l}\text { pre: } 42.7(17.5) \text {; post: } 62.9(13) \\
\text { p<0.05; t0>t1 }\end{array}$ & NA & NA \\
\hline $\begin{array}{l}\text { Tang et al. } 2021 \\
(22)\end{array}$ & $\operatorname{PIF}(1 / \mathrm{min})$ & $\begin{array}{l}\text { Pre- } \\
\text { experimental }\end{array}$ & $\begin{array}{l}\text { MD: } 0.74(0.58) \\
p<0.001 ; \text { t } 0>\mathrm{t} 1\end{array}$ & NA & NA \\
\hline $\begin{array}{l}\text { Tang et al. } 2021 \\
(22)\end{array}$ & $\begin{array}{l}\text { Diaphragm } \\
\text { thickness }(\mathrm{cm})\end{array}$ & $\begin{array}{l}\text { Pre- } \\
\text { experimental }\end{array}$ & $\begin{array}{l}\mathrm{NI} \\
p>0.05 ; \mathrm{NI}\end{array}$ & NA & NA \\
\hline $\begin{array}{l}\text { Tang et al. } 2021 \\
(22)\end{array}$ & $\begin{array}{l}\text { Diaphragm } \\
\text { movement }(\mathrm{cm})\end{array}$ & $\begin{array}{l}\text { Pre- } \\
\text { experimental }\end{array}$ & $\begin{array}{l}\text { Quiet breathing: } \\
\text { NI } \\
p>0.05 \text {; NI } \\
\text { Deep breathing: } \\
\text { MD: } 0.57(1.18) \\
p=0.009 ; \text { t0 }>\text { t1 }\end{array}$ & NA & NA \\
\hline $\begin{array}{l}\text { Al Chikhanie et } \\
\text { al. } 2021 \text { (24) }\end{array}$ & $\operatorname{MEP}\left(\mathrm{cmH}_{2} \mathrm{O}\right)$ & Cohort & $\begin{array}{l}\text { pre: } 68.2(30.3) \text {; post: } 87.1(30.3) \\
p<0.05 ; \text { t } 0>\text { t1 }\end{array}$ & NA & NA \\
\hline $\begin{array}{l}\text { Chintamani et } \\
\text { al. } 2020(19)\end{array}$ & $\begin{array}{l}\text { Heart rate } \\
\text { (beats/min) }\end{array}$ & $\begin{array}{l}\text { Pre- } \\
\text { experimental }\end{array}$ & $\begin{array}{l}\text { pre: } 100(5) ; \text { post: } 69(5) \\
p<0.05 ; \text { t0 }>\text { t1 }\end{array}$ & NA & NA \\
\hline $\begin{array}{l}\text { Kofod et al. } \\
2021 \text { (26) }\end{array}$ & & $\begin{array}{l}\text { Cohort (full } \\
\text { cohort) }\end{array}$ & $\begin{array}{l}\text { pre: } 89.5 \text { (24.4); post: } 94.9(18.9) \\
p>005 ; \text { t0 > t1 }\end{array}$ & NA & NA \\
\hline $\begin{array}{l}\text { Kofod et al. } \\
2021(26)\end{array}$ & & $\begin{array}{l}\text { Cohort (excl. } \\
\text { CPAP failure) }\end{array}$ & $\begin{array}{l}\text { pre: } 91.2(26.8) \text {; post: } 98.5(19.4) \\
p>0.05 \text {; t0 >t1 }\end{array}$ & NA & NA \\
\hline $\begin{array}{l}\text { Verma et al. } \\
2021 \text { (29) }\end{array}$ & & Cohort & $\begin{array}{l}\text { pre: } 92.46 \text { (14.93); post: } 100.4 \\
(13.25) \\
p<0.001 \text {; to < t1 }\end{array}$ & NA & NA \\
\hline $\begin{array}{l}\text { Kofod et al. } \\
2021(26)\end{array}$ & $\begin{array}{l}\text { Blood pressure } \\
(\mathrm{mmHg})\end{array}$ & Cohort & $\begin{array}{l}\text { Full cohort } \\
\text { pre: } 133.6 \text { (19.1); post: } 129.3 \\
(15.2)\end{array}$ & NA & NA \\
\hline & & & $p>0.05 ;$ to $>$ t 1 & & \\
\hline & & & $\begin{array}{l}\text { Excl. CPAP failure } \\
\text { pre: } 135.2(21.5) \text {; post: } 129.4 \\
(15.2)\end{array}$ & & \\
\hline & & & $p>0.05 ; \mathrm{t} 0>\mathrm{t} 1$ & & \\
\hline
\end{tabular}

Continuous values are reported as mean (SD). CPAP: continuous positive airway pressure; NA: not applicable; MD: mean difference; MEP: maximum expiratory pressure; MIP: maximum inspiratory pressure; NI: no information; PIF: peak inspiratory flow.

possible missing data or about how missing data would have been handled if present $(19,25)$. In some studies, the outcome measures were well defined and objective tools were used to measure these outcomes. However, in some studies, the way the outcome was measured was not well defined, or the tool used to measure the outcome was subjective. In addition, the participants and assessors were usually not blinded to intervention allocation (16, $24,26)$. There was also missing information regarding the inclusion and exclusion criteria used to determine the eligibility of participants (23-25), or it was unclear when and where participants were recruited (28). These aspects can all lead to bias. Some of the studies were conducted retrospectively and individuals were selected after the outcome had been measured, both of which can lead to selection bias $(20,23-26,29)$. This last factor can lead to an overestimation of the results, since the outcome measure is already measured and results are already known in a retrospective study. In most studies, the risk of reporting bias was low. However, in 3 studies, the risk of bias was scored moderate or high $(25,27,28)$. In Udina et al.'s study (28) only the results of the 6MWT of a subsample were reported. There was no information on how the whole sample scored on this test (28). In Hermann et al.'s study (25) there was inadequate reporting on which results were significant. Lastly, in Spielmanns et al.'s study the results of the pre-post analysis were not reported for all outcome measures mentioned (27). Lastly, checking the studies for publication bias was not always possible, since most of them were not registered and no pre-registered protocols were available. Researchers could only report the outcome measure on which physical therapy had a positive effect, which could lead to an overestimation of the benefits of physical therapy.

Overall, the risk of bias of the included studies is moderate-to-high. This means that the internal validity of the studies is low and conclusions drawn from these results should be interpreted with caution.

\section{Qualitative synthesis of results}

Pulmonary outcome measures were reported in 8 studies $(15,17-19,22,24,26,29)$, with in total 22 different 
parameters. Detailed results of all included pulmonary outcome measures are shown in Table VI. Given the heterogeneity amongst the included outcome measures it was decided not to pool the results. Nevertheless, all studies reported significant improvements in pulmonary function after the physical therapy intervention (see Table VI). A variety of interventions were used to improve the pulmonary function of COVID-19 patients: (i) respiratory rehabilitation consisting of breathing and cough exercises, respiratory muscle training, stretching respiratory muscles and prone lying; (ii) CPAP treatment; (iii) physical rehabilitation consisting of motor strengthening, mobilizations, bed mobility exercises; and (iv) aerobic training.

Liu et al.'s RCT (15) demonstrated that 6 weeks of respiratory rehabilitation improved the forced vital capacity (pre: $1.79(0.53) \mathrm{L}$; post: $2.36(0.49) \mathrm{L} ; p<0.05)$, the forced expiratory volume in $1 \mathrm{~s}$ (pre: $1.10(0.08) \mathrm{L}$; post: $1.44(0.25) \mathrm{L} ; p<0.05)$, the Tiffeneau-index (pre: $60.48(6.39) \%$; post: $68.19(6.05) \% ; p<0.05)$ and the diffusion capacity (pre: 60.3 (11.3) \%; post: 78.1 (12.3) $\% ; p<0.05$ ), in an elderly COVID-19 population (all patients $>65$ years). The intervention group also scored higher post-intervention on these variables compared with the control group (15). Abodonya et al.'s non-RCT (17) also reported improvements in pulmonary function after only 2 weeks of inspiratory muscle training in an ICU COVID-19 population. The intervention group improved more over time than the control group (17). In Ahmed et al.'s pre-experimental study (18), 5 weeks of aerobic training in combination with breathing exercises seemed to be effective to improve dyspnoea experienced by COVID-19 patients (BORG score pre: 4.5 (0.2); post: $3.1(0.1) ; p<0.001)(18)$. Chintamani $\&$ Burungale (19) showed that a structured exercise programme can improve oxygen saturation (pre: 90 (5) \%; post: $98(2) \%$; $p<0.05)$, respiratory rate (pre: 45 (3); post: 20 (2); $p<0.05$ ), dyspnoea (BORG score pre: 7 (3); post: $0(1) ; p<0.001)$ and heart rate (pre: 100 (5); post: $69(5) ; p<0.05)$ in ICU COVID-19 patients. The number of active coughs extractions (pre: 0 (1); post: 5 (2); $p<0.001$ ) and the $\mathrm{X}$-ray images from the lung also improved after 7 days (19). Tang et al.'s pre-experimental study (22) investigated the effect of a specific home exercise, namely Liuzijue, in discharged COVID-19 patients. After 4 weeks, the maxima inspiratory pressure (mean difference (MD): 13.46 (20.06) $\mathrm{cmH} 2 \mathrm{O} ; p<0.001$ ) and peak inspiratory flow (MD: 0.74 (0.58) $1 / \mathrm{min} ; p<0.001)$ increased, the movement of the diaphragm during deep breathing improved (MD: 0.57 $(1.18) \mathrm{cm} ; p=0.009)$ and dyspnoea decreased $(p=0.022)$ as well in these patients (22). The cohort study of Al Chikhanie et al. (24), determined the effect of pulmonary rehabilitation in general. The study showed that the forced expiratory volume in 1/s (pre: 66.7 (16) \%; post:
$81.2(14.2) \% ; p<0.05)$, the forced vital capacity (pre: $59.1(15.2) \%$; post: $72.9(15.2) \% ; p<0.05)$ and the maximal inspiratory pressure (pre: $42.7(17.5) \mathrm{cmH}_{2} \mathrm{O}$; post: $\left.62.9(13) \mathrm{cmH}_{2} \mathrm{O} ; p<0.05\right)$ and maximal expiratory pressure (pre: $68.2(30.3) \mathrm{cmH}_{2} \mathrm{O}$; post: $87.1(30.3)$ $\left.\mathrm{cmH}_{2} \mathrm{O} ; p<0.05\right)$ improved significantly after pulmonary rehabilitation (24). Kofod et al.'s study (26) was the only one included in this review to examine the effect of CPAP in COVID-19 patients with respiratory failure. In the full cohort, both respiratory rate (pre: 28.6 (7.6); post: $26.9(6.2) ; p=0.002)$ and oxygen saturation (pre: 90.7 (3.5) \%; post: 92.7 (3.2) \%; $p<0.001)$ improved immediately after administering CPAP. Less oxygen supplementation was needed (pre: 27.4 (13.3) 1/min; post: $23.3(10.7) 1 / \mathrm{min} ; p<0.001)$. The same conclusion could be drawn when the participants for whom CPAP failed were excluded from the study. The oxygenation index improved significantly over time $(p=0.02)$ in the CPAP success group, while it decreased significantly over time in the CPAP failure group $(p<0.001)(26)$. Finally, Verma et al.'s cohort study (29) proved that physical therapy improved heart rate (pre: 92.46 beats/ min (14.93); post: 100.4 beats/min $(13.25) ; p<0.001)$ and that, after 2 weeks, less oxygen supplementation was needed (pre: 60.9 (25.39) 1/min; post: 34.76 (24.98) $1 / \mathrm{min} ; p<0.001)$.

Physical outcome measures. These were reported in 11 studies $(15,17,18,20-25,27,28)$, with, in total, 10 different parameters. Detailed results of all included physical outcome measures are shown in Table VII. Given the heterogeneity amongst the included outcome measures it was decided not to pool the results. However, all studies reported significant improvements in one or more physical outcome measures after the physical therapy intervention (see Table VII). A variety of interventions were used to improve the physical function of COVID-19 patients: (i) respiratory rehabilitation consisting of breathing and cough exercises, respiratory muscle training, stretching respiratory muscles, and prone lying; (ii) CPAP treatment; (iii) physical rehabilitation consisting of motor strengthening, mobilizations, bed mobility exercises; and (iv) aerobic training.

Liu et al.'s RCT (15) demonstrated that exercise endurance measured with the 6MWT improved (pre: 162.7 (72) m; post: $212.3(82.5) \mathrm{m} ; p<0.05)$ after 6 weeks of respiratory rehabilitation. The intervention group also scored higher post-intervention than the control group (I: 212.3 (82.5) m; C: 157.2 (71.7) m; $p<0.05)$. However, there was no improvement in functional independence (15). Abodonya et al. (17) reviewed the effect of 2 weeks of inspiratory muscle training on exercise capacity with a non-randomized controlled study design. There was a significant improvement after the intervention compared with the baseline assessment (6MWT pre: $332.6(34.5) \mathrm{m}$; post: 
p. 10 of 16 R. Debeuf et al.

376.5 (39.4) $\mathrm{m} ; p<0.001)$. The intervention group also improved more compared with the control group who received usual care (I: 376.5 (39.4) m; C: 334.8 (38.2) $\mathrm{m} ; p=0.028)$ (17). Ahmed et al. (18) investigated the effect of aerobic training in combination with breathing exercises on exercise capacity in symptomatic

Table VII. Results per outcome: physical function

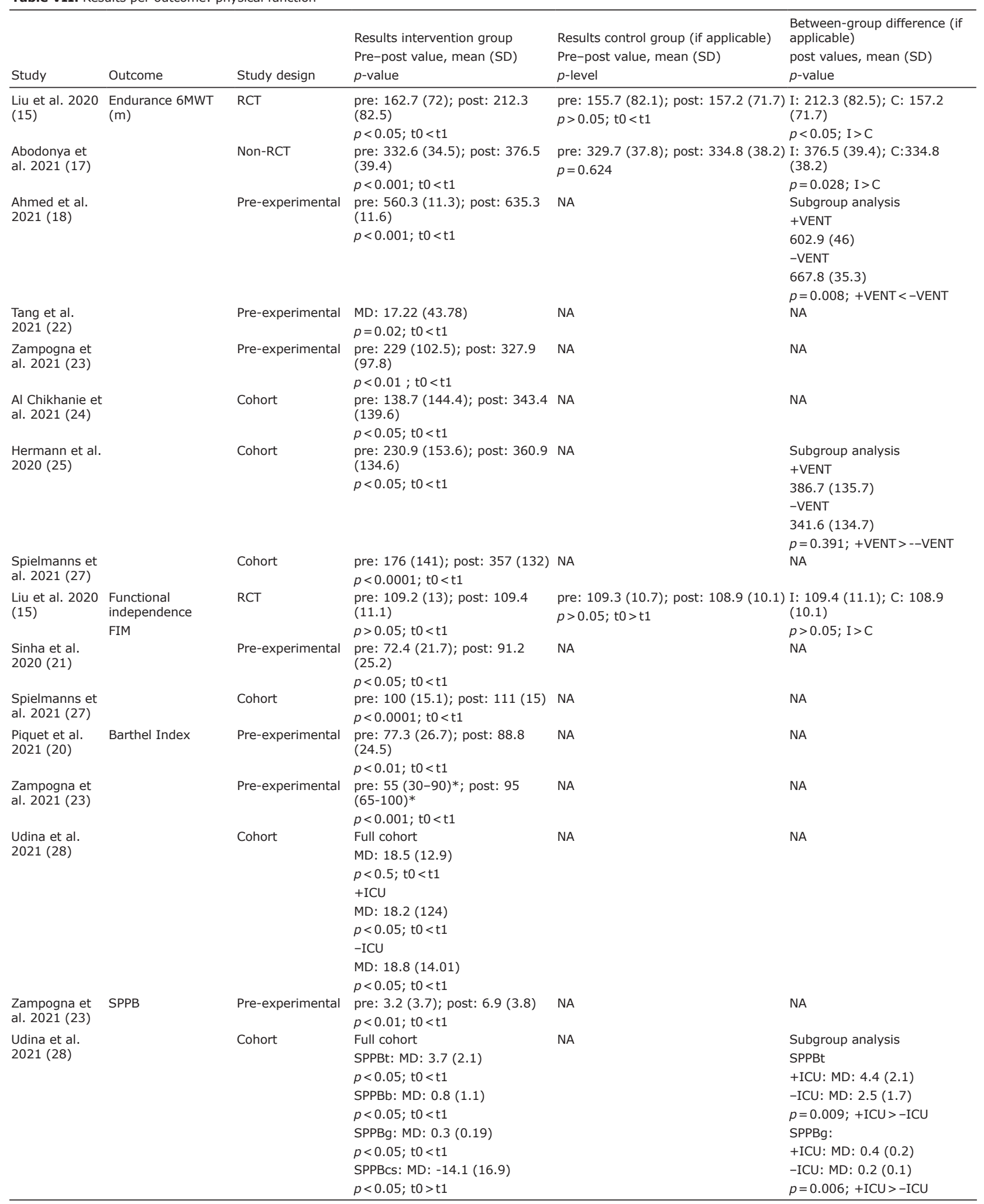




\begin{tabular}{|c|c|c|c|c|c|}
\hline Study & Outcome & Study design & $\begin{array}{l}\text { Results intervention group } \\
\text { Pre-post value, mean (SD) } \\
p \text {-value }\end{array}$ & $\begin{array}{l}\text { Results control group (if applicable) } \\
\text { Pre-post value, mean (SD) } \\
p \text {-level }\end{array}$ & $\begin{array}{l}\text { Between-group difference (if } \\
\text { applicable) } \\
\text { post values, mean (SD) } \\
p \text {-value }\end{array}$ \\
\hline & & & $\begin{array}{l}+ \text { ICU } \\
\text { SPPBt: MD: } 4.4(2.1) \\
p<0.05 ; \text { t0 }<\mathrm{t} 1 \\
\text { SPPBb: MD: } 1.1(1.2) \\
p<0.05 ; \text { t0 }<\mathrm{t} 1 \\
\text { SPPBg: MD: } 0.4(0.2) \\
p<0.05 ; \text { t0 }<\mathrm{t} 1 \\
\text { SPPBCS: MD: }-15.3(16.9) \\
p<0.05 ; \text { t0 }>\mathrm{t} 1 \\
\text {-ICU } \\
\text { SPPBt: MD: } 2.5(1.7) \\
p<0.05 ; \text { t0 }<\mathrm{t} 1 \\
\text { SPPBb: MD: } 0.2(0.1) \\
p<0.05 ; \text { t0 }<\mathrm{t} 1 \\
\text { SPPBg: MD: } 0.2(0.1) \\
p<0.05 ; \text { t0 }<\mathrm{t} 1 \\
\text { SPPBCs: MD: }-12.2(17.6) \\
p<0.05 ; \text { t0 }>\mathrm{t} 1\end{array}$ & & \\
\hline $\begin{array}{l}\text { Udina et al. } \\
2021 \text { (28) }\end{array}$ & FAC & Cohort & $\begin{array}{l}\text { Full cohort } \\
\text { MD: } 14(42.4)^{*} \\
p<0.05 ; \text { t0 }<\mathrm{t} 1 \\
+\mathrm{ICU} \\
\mathrm{MD}: 7(35)^{*} \\
p<0.05 ; \text { t0 }<\mathrm{t} 1 \\
-\mathrm{ICU} \\
\mathrm{MD}: 7(53.8)^{*} \\
p<0.05 ; \mathrm{t} 0<\mathrm{t} 1\end{array}$ & NA & NA \\
\hline $\begin{array}{l}\text { Piquet et al. } \\
2021 \text { (20) }\end{array}$ & $\begin{array}{l}\text { Muscle strength } \\
\text { Sit to stand }(\mathrm{Hz})\end{array}$ & Pre-experimental & $\begin{array}{l}\text { pre: } 0.27(0.16) \text {; post: } 0.37 \\
(0.16) \\
p<0.001 ; \text { t } 0<\mathrm{t} 1\end{array}$ & NA & NA \\
\hline $\begin{array}{l}\text { Al Chikhanie et } \\
\text { al. } 2021(24)\end{array}$ & & Cohort & $\begin{array}{l}\text { pre: } 18.1(8) ; \text { post: } 23.5(8.5) \\
p<0.05 ; \text { t } 0<\text { t1 }\end{array}$ & NA & NA \\
\hline $\begin{array}{l}\text { Al Chikhanie et } \\
\text { al. } 2021(24)\end{array}$ & $\begin{array}{l}\text { Quadriceps muscle } \\
\text { strength }(\mathrm{kg})\end{array}$ & Cohort & $\begin{array}{l}\text { pre: } 14.2(10.6) ; \text { post } 25.2 \\
(11.7) \\
p<0.05 ; \text { t } 0<\mathrm{t} 1\end{array}$ & NA & NA \\
\hline $\begin{array}{l}\text { Sinha et al. } \\
2020(21)\end{array}$ & $\begin{array}{l}\text { Balance } \\
\text { Tinetti }\end{array}$ & Pre-experimental & $\begin{array}{l}\text { pre: } 11.9(3.6) ; \text { post: } 21.9(5.5) \\
p<0.05 ; \text { t } 0<\mathrm{t} 1\end{array}$ & NA & NA \\
\hline $\begin{array}{l}\text { Al Chikhanie et } \\
\text { al. } 2021(24)\end{array}$ & & Cohort & $\begin{array}{l}\text { pre: } 25 \text { (3); post: } 27.5(1) \\
p<0.05 ; \text { t } 0<\mathrm{t} 1\end{array}$ & NA & NA \\
\hline $\begin{array}{l}\text { Udina et al. } \\
2021 \text { (28) }\end{array}$ & Single-leg stance & Cohort & $\begin{array}{l}\text { Full cohort } \\
\text { MD: } 10(30.3)^{*} \\
p<0.05 ; \text { t0 }<\text { t1 } \\
+ \text { ICU } \\
\text { MD: } 9(45)^{*} \\
p<0.05 ; \text { t0 }<\mathrm{t} 1 \\
-\mathrm{ICU} \\
\mathrm{MD}: 1(7.7)^{*} \\
p>0.05 ; \text { t0 }\end{array}$ & NA & NA \\
\hline
\end{tabular}

Continuous values are reported as mean (SD) or N (\%)*. FAC: functional ambulation category; + ICU: patients who stayed at the intensive care unit; -ICU: patients who did not stay at the intensive care unit; MD: mean difference; NA: not applicable; SPPBb: Short Physical Performance Battery balance score; SPPBCs: Short Physical Performance Battery chair stand time; SPPBg: Short Physical Performance Battery gait speed; SPPBt: Short Physical Performance Battery total score.

COVID-19 patients. The distance walked in $6 \mathrm{~min}$ also improved significantly in this study (pre: 560.3 (11.3) m; post: $635.3(11.6) \mathrm{m} ; p<0.001)$. Patients who had received mechanical ventilation improved less than patients who did not receive mechanical ventilation (+VENT: 602.9 (46) m; -VENT: 667.8 (35.3) m; $p=0.008)$ (18). Piquet et al.'s pre-experimental study
(20) showed that activities of daily living (ADL) (BI pre: 77.3 (26.7); post: $88.8(24.5) ; p<0.01)$, handgrip strength (pre: 18.1 (9.25) kg; post: 20.9 (8.9) kg; $p<0.001$ ) and lower extremity strength (sit-to-stand frequency pre: $0.27(0.16) \mathrm{Hz}$; post: $0.37(0.16) \mathrm{Hz}$; $p<0.001$ ) increased significantly after physical therapy in COVID-19 patients. Patients who were admitted to 
the ICU showed greater improvement in grip strength compared with patients who were not admitted to the ICU (+ICU: MD 3.3 (3.1) kg; -ICU: MD 0.99 (3.7) $\mathrm{kg} ; p=0.049)$ (20). The long-term effect of structured exercise was investigated in Sinha et al.'s pre-experimental study (21). Both independence (Functional Independence Measure (FIM) score pre: 72.4 (21.7); post: $91.2(25.2) ; p<0.05)$ and mobility (Tinetti score pre: 11.9 (3.6); post: $21.9(5.5) ; p<0.05)$ improved significantly after the intervention (21). Tang et al.'s study (22) investigated the effect of 4 weeks of Liuzijue on exercise capacity and also reported improvements in the distance walked in 6 min (MD: 17.22 (43.78) $\mathrm{m} ; p=0.02$ ) (22). Zampogna et al. (23) showed that patient-tailored pulmonary rehabilitation, based on age, clinical severity, length of immobilization and comorbidities, has a positive effect on lower extremity function (Short Physical Performance Battery (SPPB) score pre: 3.2 (3.7); post: $6.9(3.8) ; p<0.01)$, exercise tolerance (6MWT pre: 229 (102.5) m; post: 327.9 (97.8) $\mathrm{m} ; p<0.01)$ and disability in COVID-19 patients who did not have any functional limitations

Table VIII. Results per outcome: psychosocial function

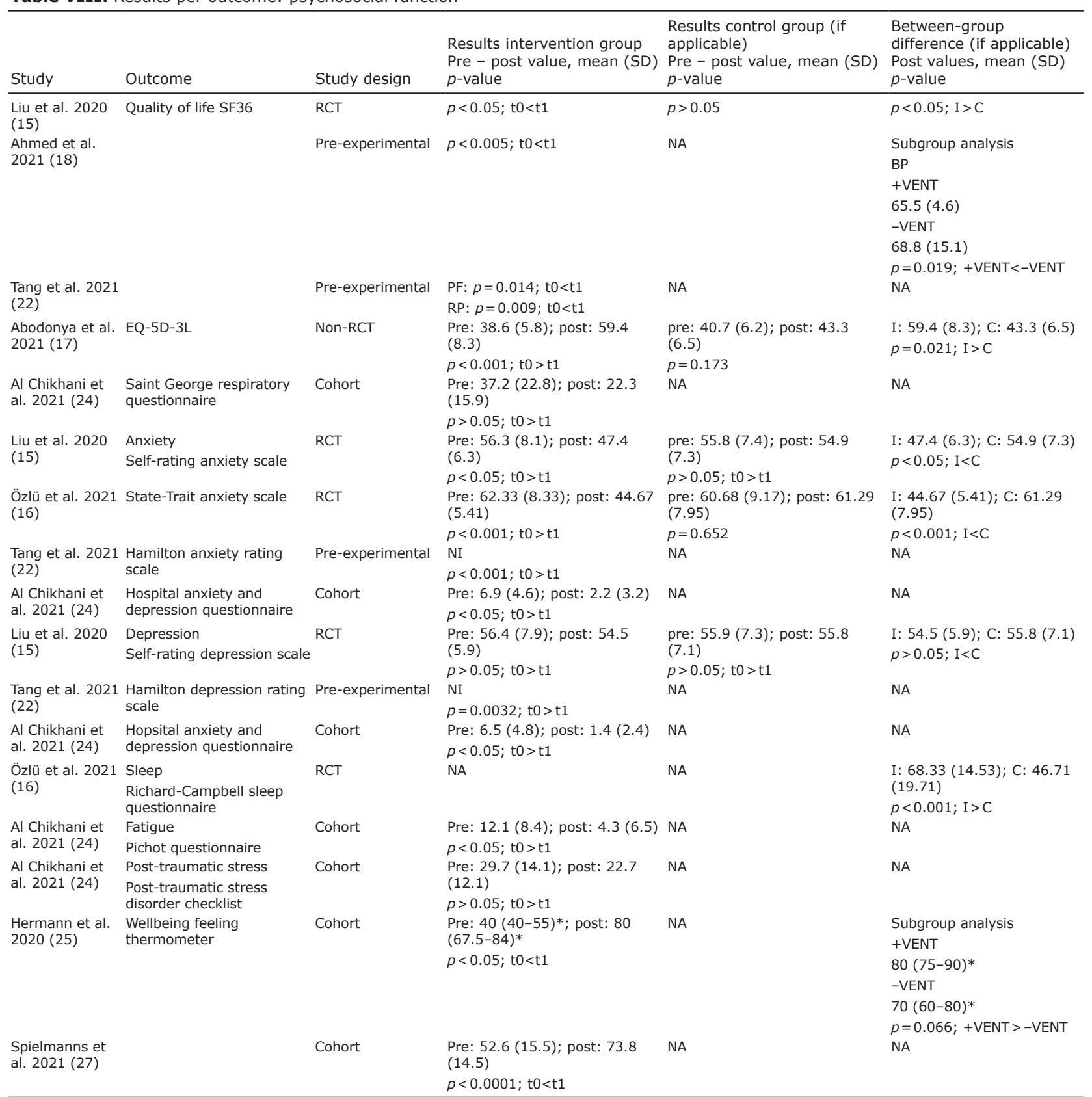

Continuous values are reported as mean (SD) or mean (CI)*. BP: bodily pain; C: control; EQ-5D-3L: EuroQuality-5Dimensions-3Levels; I: intervention; NA: not applicable; NI: no information; PF: physical functioning; RCT: randomized controlled trial; RP: role-physical; SF36: 36-Item Short Form Health Survey; +VENT: patients who endured mechanical ventilation; -VENT: patients who did not endure mechanical ventilation. 
prior to the COVID infection (23). Al Chikhanie et al.'s cohort study (24) found that both walking performance (6MWT pre: 138.7 (144.4) m; post: 343.4 (139.6) m; $p<0.05)$ and muscle strength improved after pulmonary rehabilitation. Hermann et al.'s cohort study (25) showed that exercise capacity improved (6MWT pre: $230.9(153.6) \mathrm{m}$; post: $360.9(134.6) \mathrm{m} ; p<0.05)$ after 20 days of cardiopulmonary rehabilitation and that there was no significant difference between patients who received mechanical ventilation and those who did not. Spielmanns et al. (27) concluded that, after 2 weeks of pulmonary rehabilitation, both exercise capacity (6MWT pre: 176 (141) m; post: 357 (132) m; $p<0.0001$ ) and disability (FIM score pre: 100 (15.1); post: 111 (15); $p<0.0001)$ improved in COVID-19 patients. Once again, patients improved their distance walked in the 6MWT (27). Lastly, Udina et al. (28) investigated the effect of multicomponent therapeutic exercises in COVID-19 patients. The study assessed the total cohort, as well as patients who received ICU care and those who did not. After the intervention, both ADL activities and physical performance improved significantly in all groups. Only the balance item in the SPPB did not differ significantly from baseline in patients who received ICU care. Significantly more participants were able to walk unassisted and were able to perform the single-leg stance test. However, there was no significant difference in the number of patients who were able to perform the single-leg stance test among participants who did not receive ICU care (28).

Psychosocial function. Psychosocial function was reported in 8 studies $(15-18,22,24,25,27)$, with a total of 14 different parameters. Detailed results of the psychosocial outcome measures are shown in Table VIII. Given the heterogeneity amongst the included outcome measures it was decided not to pool the results. All studies reported significant improvements in at least one or more psychosocial outcome measures after the physical therapy intervention (see Table VIII). A variety of interventions were used to improve the physical function of COVID-19 patients: (i) respiratory rehabilitation, consisting of breathing and cough exercises, respiratory muscle training, stretching respiratory muscles, and muscle relaxation exercises; (ii) physical rehabilitation, consisting of motor strengthening, mobilizations, bed mobility exercises; and (iii) aerobic training.

According to Liu et al.'s RCT (15), QoL and anxiety, but not depression, improved after 6 weeks of pulmonary rehabilitation in COVID-19 patients. The intervention group scored better post-intervention compared with the control group (15). Similar results for anxiety were found in Özlü et al.'s RCT (16). They concluded that, after 5 days of progressive muscle relaxation, the anxiety scores of COVID-19 patients improved in the interven- tion group (State-Trait Anxiety Inventory (STAI) score pre: 62.33 (8.33); post: 44.67 (5.41); $p<0.001$ ). No information regarding the pre-post difference in sleep quality was provided. Nevertheless, the intervention group scored higher post-intervention than the control group for both anxiety (STAI score I: 44.67 (5.41); C: $61.29(7.95) ; p<0.001)$ and sleep quality (RCSQ score I: 68.33 (14.53); C: 46.71 (19.71); $p<0.001)$ (16). Abodonya et al. (17) also investigated the effect of 2 weeks of inspiratory muscle training on QoL in a non-RCT. The intervention group had a better QoL postintervention (EQ-5D-3L score pre: 38.5 (5.8); post: 59.4 (8.3); $p<0.001)$ and improvements were significantly higher compared with the control group (EQ-5D-3L score I: 59.4 (8.3); C: 43.3 (6.5); $p=0.021)(17)$. The preexperimental study of Ahmed et al. (18) investigated the effect of aerobic training in combination with breathing exercises on QoL in symptomatic COVID-19 patients. Patients had a better QoL after 5 weeks of training (18). Tang et al.'s pre-experimental study of (22) showed that, after 4 weeks of Liuzijue training, QoL improved in discharged COVID-19 patients, but only in the physical functioning $(p=0.014)$ and in the role-physical aspect $(p=0.009)$ of the 36-Item Short Form Health Survey (SF-36) questionnaire. Patients also experienced less anxiety $(p<0.001)$ and depression $(p=0.0032)$ after the intervention (22). According to Al Chikhanie et al.'s cohort study (24) QoL and post-traumatic stress did not improve in COVID-19 patients after pulmonary rehabilitation. However, participants experienced less anxiety (HADS score pre: 6.9 (4.6); post: 2.2 (3.2); $p<0.05$ ) and had fewer depressive feelings (HADS score pre: 6.5 (4.8); post: $1.4(2.4) ; p<0.05)$ after the intervention (24). In Hermann et al.'s cohort study (25), the effect of cardiopulmonary rehabilitation on the wellbeing of COVID-19 patients was investigated. Patients felt significantly better after the intervention. However, there was no significant difference between patients who received mechanical ventilation and those who did not (25). Lastly, Spielmanns et al.'s cohort study of (27) concluded that 2 weeks of pulmonary rehabilitation can improve well-being in COVID-19 patients (feeling thermometer pre: 52.6 (15.5); post: $73.8(14.5) ; p<0.0001)$.

\section{DISCUSSION}

This rapid review aimed to provide an overview of the effect physical therapy can have on impairments in COVID-19 patients. A variety of physical therapy interventions were provided to COVID-19 patients in different settings. Several interventions could be distinguished. While some interventions focused primarily on pulmonary rehabilitation, consisting of breathing and cough exercises, CPAP treatment, 
respiratory muscle training and stretching, other interventions combined pulmonary rehabilitation with physical rehabilitation and/or aerobic training. Pulmonary rehabilitation, both with and without a physical/ aerobic component, was found to positively affect the pulmonary, physical, and psychosocial functions of COVID-19 patients.

As the COVID-19 pandemic has evolved, longterm symptoms and functional problems related to the SARS-CoV-2 infection have became apparent. Approximately $5-10 \%$ of infected people experience prolonged symptoms, with the predominant symptoms being overall reduced physical capacity, fatigue and muscle weakness $(30,31)$. Since the start of the pandemic, the need for rehabilitation has been highlighted, and that patients with long-COVID (those who continue to experience COVID-19 symptoms for longer than usual after initially contracting the SARS-CoV-2 virus) may benefit from physical therapy interventions because of the severe impact on ADL, participation and QoL. However, the majority of the included studies focused on hospitalized COVID-19 patients, either in ICU or other inpatient units. Only 3 studies assessed the effect of physical therapy on discharged COVID-19 patients, which highlights the need for high-quality studies on rehabilitation interventions in this specific population. Currently, recommendations for the interventions are based on research performed in patients presenting similar difficulties, but caused by other diseases (chronic obstructive pulmonary disease (COPD), cancer rehabilitation, etc.). According to these recommendations, patients are advised to perform light aerobic and breathing exercises daily. However, such a generic "one-size-fits-all" physical therapy programme may not be suitable for every patient. In addition, due to long-COVID, patients' feelings of fatigue, appropriate personalized and behavioural approaches are key to achieving optimal rehabilitation outcomes when implementing a physical training programme.

Besides the pulmonary and physical problems, most COVID-19 patients show some degree of dysphagia and malnutrition $(32,33)$. In addition, 37\% (range 29-52\%) of hospitalized COVID-19 patients have a weight loss of $\geq 5 \%$, which defines cachexia. This COVID-19-induced cachexia is accompanied by muscle mass loss and relatively high percentage of fat tissue, which is also seen in other chronic illness-associated forms of cachexia. Moreover, the characteristics of COVID-19-related loss of taste and appetite, fever, inflammation, catabolic-anabolic imbalance and endocrine dysfunction further increase the risk of developing cachexia (33). A patient-tailored rehabilitation programme, combined with nutritional optimization and counselling, may therefore lead to a more rapid improvement in functional performance compared with a standard physiotherapy programme in patients with long-term effects of COVID-19, and is worth implementing in future research.

\section{Strengths and limitations}

A strength of this rapid review is the broad scope of assessed outcome variables, providing readers a holistic view on the possible benefits of physical therapy in COVID-19 patients. Furthermore, the interventions administered to the patients were often described in detail, which makes replication and implementation easier. Lastly, relatively large sample sizes were used in the included studies, which gives these studies statistical power.

However, when interpreting the results, the moderateto-poor methodological quality of the included studies must be taken into account. Another important key issue was the absence of a control group in most of the included studies. Hence, no causal relationship between an improvement in an outcome measure and the intervention can be determined. However, as stated in some studies, it is highly unethical to deny patients therapy when it is clearly recommended by experts in the field.

This rapid review is the first to discuss physical therapy in its entirety and the effect it has on COVID-19 patients. The new information provided by this review supplements previous reviews and guidelines, which are often based on expert opinion. However, many studies have already been conducted, and many more are still ongoing (124 studies are registered in clinicaltrials. gov; =covid+rehabilitation). Therefore, it is of great importance that the guidelines are reviewed regularly and, if necessary, updated to provide patients with the best possible care.

In conclusion, physical therapy is an important and necessary intervention at all stages of COVID-19 recovery. Pulmonary rehabilitation, both with and without a physical/aerobic component, can improve pulmonary, physical, and psychosocial functions in COVID-19 patients. However, this review shows that more high-quality research, focusing on all stages of COVID-19 recovery, is necessary to provide clinicians with clear evidence-based guidelines. Investigating more personalized and behavioural approaches, as well as the incorporation of other interventions, such as nutritional optimization and counselling, is highly recommended.

\section{ACKNOWLEDGEMENTS}

EDK is a strategic basic research fellow funded by the Research Foundation Flanders (FWO). RD is research fellow funded by Flanders Innovation \& Entrepreneurship.

The authors have no conflicts of interest to declare. 


\section{REFERENCES}

1. Coronavirus (COVID-19) Dashboard. Available from https://covid19.who.int/. [Cited on 13 October 2021].

2. Wittmer VL, Paro FM, Duarte H, Capellini VK, BarbalhoMoulim MC, Early mobilization and physical exercise in patients with COVID-19: A narrative literature review. Complement Ther Clin Pract 2021; 43: 101364.

3. Thomas P, Baldwin C, Bisset B, Boden I, Gosselink R, Granger $\mathrm{CL}$, et al. Physiotherapy management for COVID-19 in the acute hospital setting: clinical practice recommendations. J Physiother 2020; 66: 73-82.

4. Vitacca M, Carone M, Clini EM, Paneroni M, Lazzeri M, Lanza $A$ et al. Joint Statement on the Role of Respiratory Rehabilitation in the COVID-19 Crisis: The Italian Position Paper. Respiration 2020; 99: 493-499.

5. Fan E, Dowdy DW, Colantuoni E, Mendez-Tellez PA, Sevransky JE, Shanholtz C, et al. Physical complications in acute lung injury survivors: a two-year longitudinal prospective study. Crit Care Med 2014; 42: 849-59.

6. Baricich A, Borg MB, Cuneo D, Cadario E, Azzolina D, Balbo $P E$, et al. Midterm functional sequelae and implications in rehabilitation after COVID-19: a cross-sectional study. Eur J Phys Rehabil Med 2021; 57: 199-207.

7. Smondack P, Gravier FE, Prieur G, Repel A, Muir JF, Cuvelier $A$, et al. [Physiotherapy and COVID-19. From intensive care unit to home care-An overview of international guidelines.] Rev Mal Respir 2020; 37: 811-822.

8. Righetti RF, Onoue MA, Politi FVA, Teixeira DT, Souza PN, Kondo CS, et al. Physiotherapy Care of Patients with Coronavirus Disease 2019 (COVID-19) - A Brazilian Experience. Clinics (Sao Paulo) 2020; 75: e2017.

9. Felten-Barentsz KM, van Oorsouw R, Klooster E, Koenders $\mathrm{N}$, Driehuis $\mathrm{F}$, Hulzebos $\mathrm{EHJ}$, et al. Recommendations for Hospital-Based Physical Therapists Managing Patients With COVID-19. Phys Ther 2020; 100: 1444-1457.

10. Page MJ, McKenzie JE, Bossuyt PM, Boutron I, Hoffman TC, Mulrow CD et al. The PRISMA 2020 statement: An updated guideline for reporting systematic reviews. J Clin Epidemiol 2021; 134: 178-189.

11. Ouzzani M, Hammady H, Fedorowicz Z, Elmagarmid A. Rayyan-a web and mobile app for systematic reviews. Systematic Reviews 2016; 5: 210.

12. Sterne JAC, Savovic J, Page MJ, Elbers RG, Blencowe NS, Boutron I, et al. RoB 2: a revised tool for assessing risk of bias in randomised trials. BMJ 2019; 366: 14898.

13. Sterne JAC, Hernán MA, Reeves BC, Savovic J, Berkman ND, Viswanathan M, et al. ROBINS-I: a tool for assessing risk of bias in non-randomised studies of interventions. BMJ 2016; 355: i4919.

14. Hayden J, van der Windt D, Cartwright J, Côté P, Bombardier C. Assessing Bias in Studies of Prognostic Factors. Annals of internal medicine 2013; 158: 280-286.

15. Liu K, Zhang W, Yang Y, Zhang J, Li Y, Chen Y. Respiratory rehabilitation in elderly patients with COVID-19: A randomized controlled study. Complement Ther Clin Pract 2020; 39: 101166.

16. Özlü I, Öztürk Z, Karaman Özlü Z, Tekin E, Gür A. The effects of progressive muscle relaxation exercises on the anxiety and sleep quality of patients with COVID-19: A randomized controlled study. Perspect Psychiatr Care 2021.

17. Abodonya AM, Abdelbasset WK, Awad EA, Elalfy IE ,Salem $\mathrm{HA}$, Elsayed SH. Inspiratory muscle training for recovered COVID-19 patients after weaning from mechanical venti- lation: A pilot control clinical study. Medicine (Baltimore) 2021; 10: e25339.

18. Ahmed I, Inam AB, Belli S, Ahmad J, Khalil W, Jafar MM. Effectiveness of aerobic exercise training program on cardio-respiratory fitness and quality of life in patients recovered from COVID-19. European Journal of Physiotherapy 2021: 6.

19. Chintamani R, Burungale M. Short term effect of exercise protocol on respiratory functions in subjects with COVID. Indian Journal of Traditional Knowledge 2020; 19: S173-S176.

20. Piquet V, Luczak C, Seiler F, Monaury J, Martini A, Ward $A B$, et al. Do Patients With COVID-19 Benefit from Rehabilitation? Functional Outcomes of the First 100 Patients in a COVID-19 Rehabilitation Unit. Arch Phys Med Rehabil 2021; 102: 1067-1074.

21. Sinha RK S, Varadharajulu G. Effectiveness of structured exercise protocol on functional performance in subjects with COVID-19. International Journal of Research in Pharmaceutical Sciences 2020; 11(Special Issue 1): 1244-1249.

22. Tang Y, Jiang J, Shen P, Li M, You H, Liu C, et al. Liuzijue is a promising exercise option for rehabilitating discharged COVID-19 patients. Medicine (Baltimore) 2021; 100: e24564.

23. Zampogna E, Paneroni M, Belli S, Aliani M, Gandolfo A, Visca D, et al. Pulmonary Rehabilitation in Patients Recovering from COVID-19. Respiration 2021; 100: 416-422.

24. Al Chikhanie $Y$, Veale $D$, Schoeffler M, Pépin JL, Verges $S$, Hérengt $F$. Effectiveness of pulmonary rehabilitation in COVID-19 respiratory failure patients post-ICU. Respir Physiol Neurobiol 2021; 287: 103639.

25. Hermann M, Pekacka-Egli AM, Witassek F, Baumgaertner R, Schoendorf S, Spielmanns M, Feasibility and Efficacy of Cardiopulmonary Rehabilitation After COVID-19. Am J Phys Med Rehabil 2020; 99: 865-869.

26. Kofod LM, Nielsen Jeschke K, Kristensen MT, Krogh-madsen R, Monfeldt Albek C, Hansen EF. COVID-19 and acute respiratory failure treated with CPAP. Eur Clin Respir J 2021; 8: 1910191

27. Spielmanns M, Pekacka-Egli AM, Schoendorf S, Windisch W, Hermann M. Effects of a Comprehensive Pulmonary Rehabilitation in Severe Post-COVID-19 Patients. Int J Environ Res Public Health 2021; 18.

28. Udina C, Ars J, Morandi A, Vilaró J, Cáceres C, Inzitari M. Rehabilitation in adult post-COVID-19 patients in postacute care with Therapeutic Exercise. J Frailty Aging 2021; 10: 297-300.

29. Verma CV, Arora RD, Mistry HM, Kubal SV, Kolwankar NS, Patil PC, et al. Changes in Mode of Oxygen Delivery and Physiological Parameters with Physiotherapy in COVID-19 Patients: A Retrospective Study. Indian J Crit Care Med 2021; 25: 317-321.

30. The Lancet. Facing up to long COVID. The Lancet 2020; 39: 1861.

31. Vaes AW, Goërtz YMJ, Van Herck M, Machado FVC, Meys R Delbressine JM et al. Recovery from COVID-19: a sprint or marathon? 6-month follow-up data from online long COVID-19 support group members. ERJ Open Res 2021; 7.

32. Brugliera $L$, Spina $A$, Castellazzi $P$, Cimino $P$, Arcuri $P$, Negro $A$, et al. Nutritional management of COVID-19 patients in a rehabilitation unit. Eur J Clin Nutr 2020; 74: 860-863.

33. Holdoway A. Addressing nutrition in the road map of recovery for those with long COVID-19. $\mathrm{Br}$ J Community Nurs 2021; 26: 218-222. 
Supplementary material to article by $R$. Debeuf et al. "Effect of physical therapy on impairments in COVID-19 patients from intensive care to home rehabilitation: A rapid review"

Appendix S1. Complete search strategy in the electronic database PubMed structured according to the Population Intervention Comparison Outcome (PICO) method

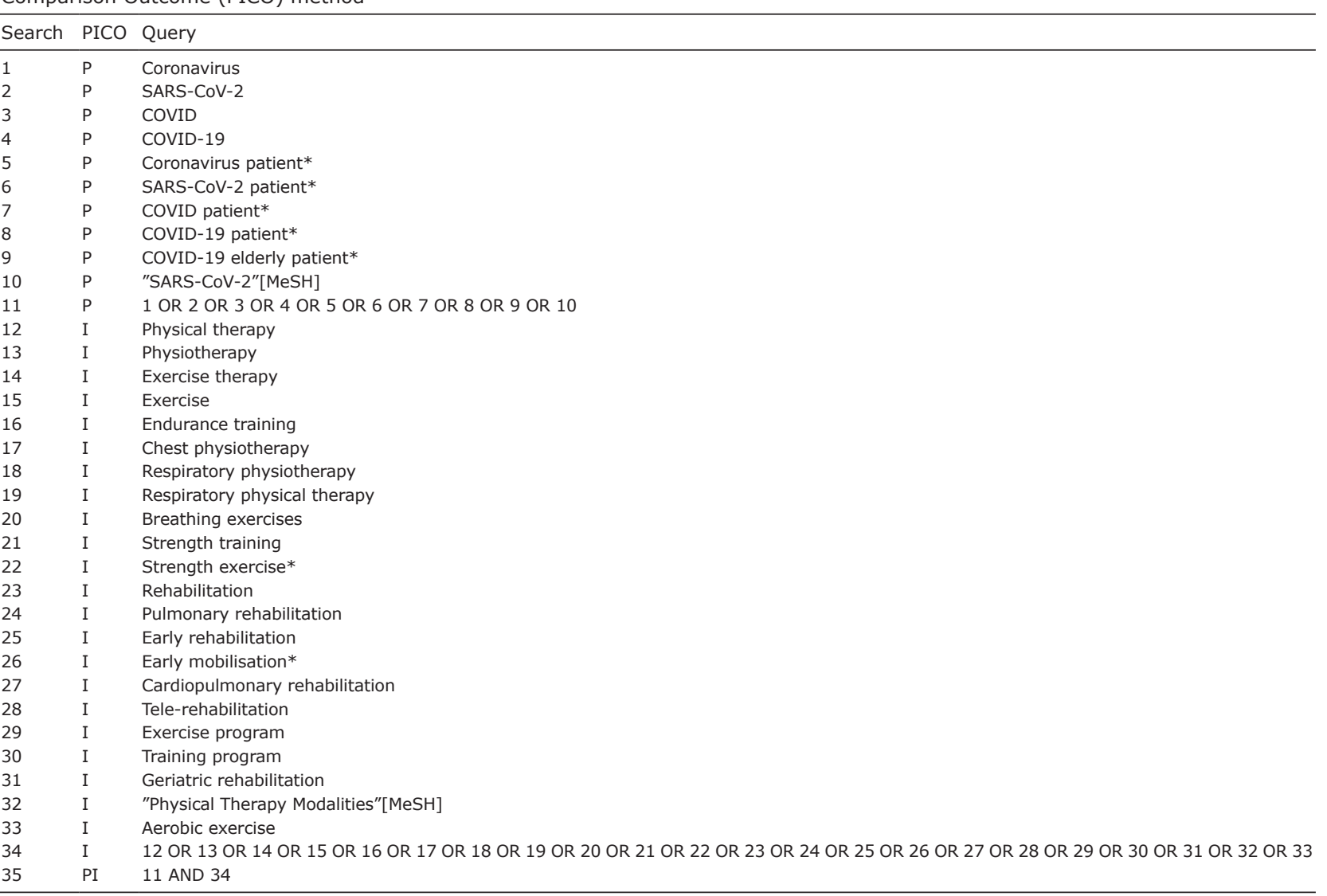

Search 35 was used to find eligible records. The same search strategy was used and adapted for the Web of Science and Scopus databases. 